\title{
Vitamin D supplementation does not improve CVD risk factors in vitamin D-insufficient subjects
}

\author{
Julia Kubiak', Per Medbøe Thorsby ${ }^{2}$, Elena Kamycheva ${ }^{1,3}$ and Rolf Jorde ${ }^{1,3}$ \\ ${ }^{1}$ Tromsø Endocrine Research Group, Department of Clinical Medicine, UiT The Arctic University of Norway, Tromsø, Norway \\ 2Department of Medical Biochemistry, Per Medbøe Thorsby, Hormone Laboratory, Oslo University Hospital, Aker, Norway \\ ${ }^{3}$ Division of Internal Medicine, University Hospital of North Norway, Tromsø, Norway \\ Correspondence should be addressed to J Kubiak: limited.mediums@gmail.com
}

\section{Abstract}

Objective: Low serum 25(OH)D levels are associated with cardiovascular disease (CVD) and some of its risk factors. However, in interventional studies, the effects of vitamin D supplementation have been uncertain, possibly due to inclusion of vitamin D-sufficient subjects. Our aim was therefore to examine effects of vitamin $D$ supplementation on CVD risk factors in vitamin D-insufficient subjects.

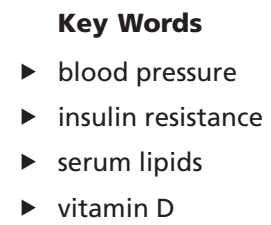

Design: Double-blinded randomized controlled trial.

Methods: A 4-month interventional study with high-dose vitamin D (100,000 IU loading dose, followed by 20,000 IU/week) or placebo with measurements of blood pressure, lipids (total-, LDL- and HDL-cholesterol, triglycerides, apolipoproteins A1 and B), and glucose metabolism parameters (blood glucose, $\mathrm{HbA}_{1 \mathrm{c}}$, serum human receptors for advanced glycation end products (sRAGE), insulin, C-peptide and HOMA-IR).

Results: A total of 422 subjects with mean serum 25(OH)D level $34 \mathrm{nmol} / \mathrm{L}$ were included, with 411 subjects completing the study. Serum 25(OH)D levels increased with $56 \mathrm{nmol} / \mathrm{L}$ and decreased with $4 \mathrm{nmol} / \mathrm{L}$ in the vitamin $\mathrm{D}$ and placebo group, respectively. We found no statistically significant differences between the two groups in any of the measured CVD risk factors, except for a minor increase in SRAGE in the vitamin D group. Stratified analyses of subjects with low baseline serum 25(OH)D levels alone, or combined with blood pressure, lipid and HOMA-IR values above the median for the cohort, did not skew the results in favour of vitamin $D$ supplementation.

Conclusion: Supplementation with vitamin D in subjects with baseline vitamin D insufficiency does not improve CVD risk factor profile.
Endocrine Connections (2018) 7, 840-849

\section{Introduction}

It is widely acknowledged that the vitamin $\mathrm{D}$ receptor (VDR), and the enzymes necessary for the hydroxylation of vitamin D to 25-hydroxyvitamin D (25(OH)D) and to the active form 1,25-dihydroxyvitamin $\mathrm{D}\left(1,25(\mathrm{OH})_{2} \mathrm{D}\right)$ are located in most tissues of the body (1). Initially related to rickets in children, vitamin $\mathrm{D}$ is nowadays considered as a vitamin/hormone with multiple functions, such as intestinal calcium absorption, involvement in cell proliferation and inflammation processes (1). Low serum 25(OH)D levels have additionally been related to numerous diseases, including cardiovascular disease (CVD) and their risk factors (2). Thus, a meta-analysis of 19 prospective studies focusing on the relation between vitamin D status and CVD found a $52 \%$ risk increase for
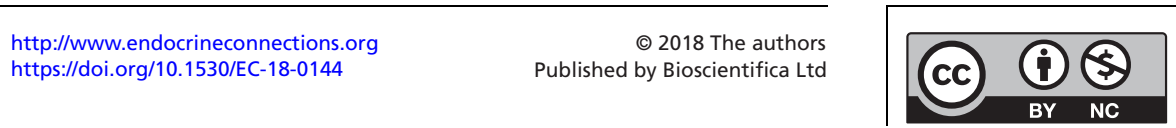
future CVD in subjects in the lowest vitamin D category (as defined by tertiles, quartiles or arbitrary cut-offs) when compared to those in the highest category) (3).

Possible explanatory factors might be the effects of vitamin D on CVD risk factors. There are associations pointing to an increase in systolic, and to a lesser degree diastolic blood pressure with decreasing serum $25(\mathrm{OH})$ D levels $(4,5)$. This may be due to activation of the renin-angiotensin system (RAS) as observed in vitamin D deficiency (6). Additionally, low serum 25(OH)D is associated with increased serum total cholesterol, LDL-cholesterol, decreased HDL-cholesterol, high apolipoprotein $\mathrm{B}$ /apolipoprotein $\mathrm{A} 1$ ratio $(7,8)$, increased serum triglycerides $(7,8)$, as well as reduced insulin sensitivity $(9,10)$. One mechanism for these effects could be vitamin $\mathrm{D}$ receptor activation related increase in CYP7A1, resulting in lowering of cholesterol levels, as observed in studies on mice (11).

However, interventional studies have yet to demonstrate with certainty effects of vitamin D supplementation on CVD risk factors, even when examined as meta-analyses. Beveridge et al. included 4541 participants from 46 randomized controlled trials (RCTs) using individual patient data, with no effect on systolic or diastolic blood pressure by vitamin D supplementation (12). In a meta-analysis by Wang et al. that included 12 clinical trials consisting of 1346 participants, no beneficial effects on total-cholesterol, HDL-cholesterol and triglycerides were found, whereas an increase in LDLcholesterol was seen (13). In Challoumas' review of 19 relevant RCTs, only one reported benefits of vitamin D supplementation on lipid profile parameters, while the rest showed no effects or even adverse outcomes (14). In a meta-analysis by Poolsup et al. including 10 trials, no effect of vitamin D on insulin resistance was found in subjects with pre-diabetes (15). And finally, in a study from 2017, Seibert et al. found no effect on CVD risk factors with $800 \mathrm{IU}$ vitamin $\mathrm{D} /$ day in 105 vitamin D-insufficient subjects (16).

However, many of these negative results might be explained by inclusion of subjects that were vitamin D sufficient, and accordingly, no effect of additional vitamin $\mathrm{D}$ were to be expected $(16,17)$. Furthermore, most of the studies included in these meta-analyses have been grossly underpowered and also complicated by differences in vitamin $\mathrm{D}$ doses and duration of trials.

In Tromsø, Northern Norway, large populationbased health surveys have been performed with 7- to 8-year intervals since 1974 (18). In the seventh survey in $2015 / 2016$, more than 21,000 subjects were included

$$
\text { http://www.endocrineconnections.org }
$$

and serum 25(OH)D measured. We therefore had the opportunity to invite a large group of subjects known to have low serum 25(OH)D levels. The aim of the present study was to investigate the effect of vitamin D supplementation on cardiovascular risk factors in people with known vitamin D insufficiency.

\section{Methods}

\section{Subjects}

In the seventh survey of the Tromsø study conducted in $2015 / 2016$, all citizens aged 40 years and above $(n=32,591)$ living in the municipality of Troms $\varnothing$ in northern Norway were invited to participate and 21,083 attended (64.7\%). With serum 25(OH)D successfully measured in 20,922 participants, 1489 males and females aged $<80$ years with serum values below the 10 th percentile $(<42 \mathrm{nmol} / \mathrm{L})$ were invited by mail to participate in the present study. This serum 25(OH)D cut-off was estimated to result in sufficient number of participants for the study. A written reminder was sent out to non-responders after 2- to 3 weeks' time. All 639 responders were screened by phone by one of the study nurses at the Clinical Research Unit at the University Hospital of North Norway. This screening included questions about medical history to exclude subjects with known granulomatous disease, diabetes, renal stones last 5 years or serious diseases that would make the subject unfit for participation, use of vitamin D supplements exceeding $800 \mathrm{IU}$ vitamin D per day and use of solarium on a regular basis, and subjects who were planning holiday(s) in tropical areas during the study period. Women of childbearing potential (below the age of 50 years) without use of acceptable contraception (hormonal, IUD) were excluded. Information about weight, height and smoking status was sent to the hospital's research department for use in the randomization procedure.

\section{Study design}

Four hundred and fifty-five subjects passed the telephone screening and came to the first visit (V1) at the Clinical Research Unit at the University Hospital of North Norway. The subjects were asked to be fasting overnight, and after signing the informed consent, medical history was taken, and blood samples were drawn, followed by measurements of height and weight (wearing light clothing and no shoes) and blood pressure. These examinations revealed that 33 subjects were unfit for further participation. The remaining 422 subjects then came to the next visit (V2)

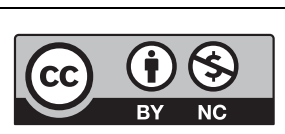

This work is licensed under a Creative Commons Attribution-NonCommercial 4.0 International License. 
within 2-5 days. The flow of inclusion is shown in Fig. 1. At this second (non-fasting) visit, blood pressure was again measured and the study drugs (cholecalciferol capsules $(20,000 \mathrm{IU}(500 \mu \mathrm{g})$ Dekristol, Mibe, Jena, Germany) or identical looking placebo capsules containing arachis oil (Ayanda GmbH \& CoKG, Falkenhagen, Germany)) were dispensed. As it takes time for serum 25(OH)D levels to increase, five capsules were given as a loading dose. The weekly dose was based on our previous intervention studies where 20,000 IU vitamin D (cholecalciferol) per week was sufficient to raise mean serum $25(\mathrm{OH}) \mathrm{D}$ levels to $\sim 80 \mathrm{nmol} / \mathrm{L}$, whilst not displaying any side effects or health risks $(19,20)$.

The randomization was stratified according to gender, vitamin D status in the Tromsø study (serum 25(OH)D

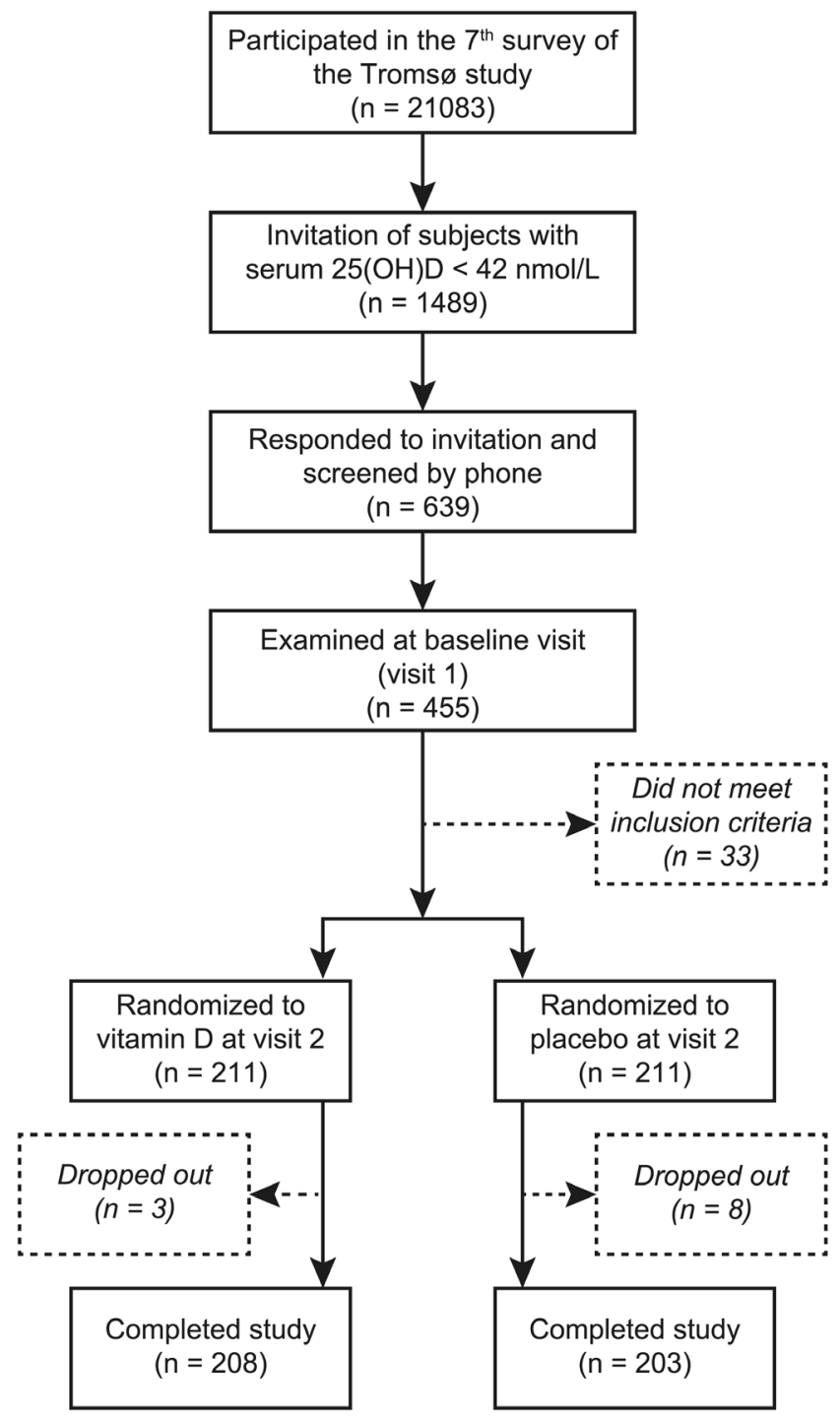

Figure 1

Flowchart for the inclusion and performance of the study.

http://www.endocrineconnections.org https://doi.org/10.1530/EC-18-0144

(C) 2018 The authors Published by Bioscientifica Ltd above/below $25 \mathrm{nmol} / \mathrm{L})$, smoking status and body mass index (BMI) above/below $27 \mathrm{~kg} / \mathrm{m}^{2}$ (self-reported height and weight). Age was not used in the randomization process. Based on this, the randomization unit assigned the subject a randomization number using a block randomization procedure. This randomization number was sent to the Clinical Research Unit for registration and to the hospital's pharmacy who dispensed the medication accordingly. Except for the pharmacy, which had no contact with the study participants, all nurses, doctors and other study personnel were blinded to the randomization throughout the study.

Two months after the first visit, the subjects were contacted by one of the study nurses, asked for adverse events and reminded to take the study medication. Two months thereafter, the third visit (V3) was performed with examinations identical to V1. The fourth visit (V4) followed a few days later, with return of study medication and the additional blood pressure measurements. Compliance was calculated as the ratio of capsules used (capsules supplied minus capsules returned) to number of weeks between V2 and V4.

The subjects were asked not to take any vitamin D supplements (including cod liver oil) during the 4-month intervention period. At the end of the study, all subjects (regardless of randomization) were advised vitamin D supplementation 800 IU per day.

\section{Measurements}

BMI was calculated as weight $(\mathrm{kg})$ divided by squared height $\left(\mathrm{m}^{2}\right)$. Blood pressure was measured after $15 \mathrm{~min}$ of rest with an automatic device (AND, A\&D Medical, Tokyo, Japan) three times with 2 min apart. The baseline (and similarly the end of study) blood pressure was calculated as ((median BP from V1) +(median BP from V2))/2. Serum calcium was analysed by an automated analyser (Modular P, Roche Diagnostics, Mannheim, Germany) with reagents from Boehringer Mannheim and a modified Jaffe reaction (Roche Hitachi 911) was used for measurement of serum creatinine. Intact parathyroid hormone (PTH) was analysed with an electrochemiluminescence immunoassay (ECLIA) using an automated clinical chemistry analyser (Cobas 6000, Roche). Serum cholesterol, HDL-cholesterol, LDL-cholesterol and triglycerides were analysed with enzymatic colorimetric methods using an automated analyser (Cobas 8000, Roche), and apolipoprotein A1 and apolipoprotein B were analysed by immune turbidimetry (Cobas 8000, Roche). Insulin and C-peptide

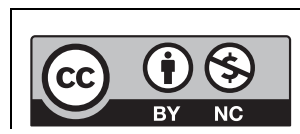

This work is licensed under a Creative Commons Attribution-NonCommercial 4.0 International License. 
were analysed by immunometry (Cobas 8000, Roche), whereas glucose was measured by photometry (Cobas 8000 , Roche). $\mathrm{HbA}_{1 \mathrm{c}}$ was measured by high-performance liquid chromatography using a Tosho G8, Tokyo, Japan. Serum concentrations of $25(\mathrm{OH}) \mathrm{D}$ were measured by an in-house liquid chromatography-tandem mass spectrometry method that detects both $25(\mathrm{OH}) \mathrm{D}_{3}$ and $25(\mathrm{OH}) \mathrm{D}_{2}$ and the sum of these presented as $25(\mathrm{OH}) \mathrm{D}$ in the results (21). The coefficient of variation (CV) for both assays is $<2 \%$. Serum human receptors for advanced glycation end products (extracellular domain) (sRAGE) was measured using ELISA kits (Quantikine, R\&D Systems) according to the manufacturer's instructions at the Hormone Laboratory, Oslo University Hospital. The inter-assay CV in our laboratory was 5.8\% (22). Insulin sensitivity was assessed with the homeostasis model (HOMA-IR) ((insulin $(\mathrm{pmol} / \mathrm{L}) \times($ glucose $(\mathrm{mmol} / \mathrm{L})) / 135)(23)$.

\section{Statistical analysis}

All variables were examined for normality of distribution, with analysis of skewness and kurtosis, visual inspection of histograms, P-P and Q-Q plots. Of the dependent variables HDL-cholesterol, triglycerides, PTH, insulin, C-peptide and HOMA-IR were not normally distributed at baseline, but were successfully corrected with log transformation and used as such in the statistical analyses. For delta values (value at end of study minus value at baseline), triglycerides, HOMA-IR and insulin had nonnormal distribution and could not be normalized by log transformation.

At baseline, comparison between the vitamin $\mathrm{D}$ and placebo groups was performed by Student's $t$-test for independent samples. The effect of the intervention was analysed per-protocol by a general linear regression model with the delta value as dependent variable, and age, gender, baseline value and randomization status as covariates. For delta triglycerides, insulin and HOMA-IR, the delta values were compared with Mann-Whitney $U$ test. Interactions between baseline values and randomization status were tested by including the baseline values (dichotomous, median-split) in the unadjusted regression models. $P$ values $<0.10$ of the interaction term were considered statistically significant.

Normally distributed data are presented as mean (SD), non-normally distributed values as median (5th, 95th percentiles). $P<0.05$ was considered statistically significant and all tests were done two-sided. IBM SPSS Statistics version 24 was used for the statistical analysis.

\section{Power calculation}

The main endpoints in the study were effects on the cardiovascular risk factors blood pressure, serum lipids and insulin resistance. The power calculation was made on the assumption that those included would have a mean serum $25(\mathrm{OH}) \mathrm{D}$ of $30 \mathrm{nmol} / \mathrm{L}$ and that those given vitamin $\mathrm{D}$ would have an increase in serum $25(\mathrm{OH}) \mathrm{D}$ to a mean level of $80 \mathrm{nmol} / \mathrm{L}$. We assumed that the maximal, realistic effect of the vitamin D supplementation would be two-third of the difference in systolic and diastolic blood pressure, serum triglycerides and HDL-cholesterol and insulin resistance (as evaluated by HOMA-IR) between those with serum $25(\mathrm{OH}) \mathrm{D}$ levels of $\sim 30 \mathrm{pmol} / \mathrm{L}$ and $\sim 80 \mathrm{nmol} / \mathrm{L}$ found in cross-sectional studies $(4,7)$. Thus, if wanting a power of 0.8 and $P<0.05$, we would need 450 subjects to show an effect of $6.7 \mathrm{mmHg}$ on systolic blood pressure, 410 subjects for $3.3 \mathrm{mmHg}$ on diastolic blood pressure, 300 subjects for $0.26 \mathrm{mmol} / \mathrm{L}$ on triglycerides, 490 subjects for $0.09 \mathrm{mmol} / \mathrm{L}$ on HDL-cholesterol and 400 subjects for 0.57 on HOMA-IR. Based on this, we would need $\sim 500$ subjects to complete the intervention to have a reasonable chance of demonstrating the anticipated effect on the primary endpoints. We assumed a dropout rate of $16 \%$, and therefore aimed to include 600 subjects in the study.

\section{Ethics}

All participants signed an informed consent form after receiving oral and written information on the study design, aim and duration. The subjects received a gift card value 200 NKR (20 Euro) to cover travel expenses in the study. The study was approved by the Regional Committee for Medical Research Ethics (REK NORD 2013/1464) and by the Norwegian Medicines Agency (2013-003514-40). The study is registered at ClinicalTrials.gov NCT02750293.

\section{Results}

The characteristics of the 422 subjects ( 224 men and 198 women) who fulfilled all inclusion criteria and came to V2 are shown in Table 1 ; mean age of 50 years, BMI $28 \mathrm{~kg} / \mathrm{m}^{2}$ and serum 25(OH)D $34 \mathrm{nmol} / \mathrm{L}$. One hundred and ten subjects were included during the summer months May-August and 312 subjects during September-March (when there is no effective UV radiation at our latitude). At baseline, the vitamin D group $(n=211)$ and the placebo group $(n=211)$ did not differ significantly except for a slight difference in serum creatinine (Table 1$)$.

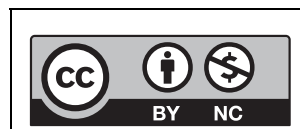

This work is licensed under a Creative Commons Attribution-NonCommercial 4.0 International License. 
Table 1 Baseline characteristics of all subjects randomized.

\begin{tabular}{|c|c|c|}
\hline & Vitamin D & Placebo \\
\hline Count & 211 & 211 \\
\hline Sex (male \%) & 53.1 & 53.1 \\
\hline Age (years) & $50(41,68)$ & $51(41,70)$ \\
\hline Smoking (\%) & 21.8 & 21.3 \\
\hline Serum 25(OH)D (nmol/L) & $32.9(11.7)$ & $35.4(13.9)$ \\
\hline BMI $\left(\mathrm{kg} / \mathrm{m}^{2}\right)$ & $27.9(5.1)$ & $27.8(4.7)$ \\
\hline Systolic BP (mmHg) & $122(13)$ & $123(12)$ \\
\hline Diastolic BP $(\mathrm{mmHg})$ & 77 (9) & $77(9)$ \\
\hline Serum creatinine $(\mu \mathrm{mol} / \mathrm{L})$ & $70.5(11.8) *$ & $72.5(13.1)$ \\
\hline Serum calcium (mmol/L) & $2.27(0.07)$ & $2.27(0.07)$ \\
\hline Serum PTH (pmol/L) & $6.2(4.1,11.2)$ & $6.6(4.3,10.4)$ \\
\hline $\begin{array}{l}\text { Serum triglycerides } \\
(\mathrm{mmol} / \mathrm{L})\end{array}$ & $1.20(0.60,2.80)$ & $1.10(0.60,2.50)$ \\
\hline Serum cholesterol ( $\mathrm{mmol} / \mathrm{L})$ & $5.22(0.97)$ & $5.13(0.96)$ \\
\hline $\begin{array}{l}\text { Serum LDL-cholesterol } \\
(\mathrm{mmol} / \mathrm{L})\end{array}$ & $3.54(0.90)$ & $3.45(0.91)$ \\
\hline $\begin{array}{l}\text { Serum HDL-cholesterol } \\
(\mathrm{mmol} / \mathrm{L})\end{array}$ & $1.30(0.90,2.20)$ & $1.40(0.80,2.20)$ \\
\hline $\begin{array}{l}\text { Serum apolipoprotein A1 } \\
(\mathrm{mmol} / \mathrm{L})\end{array}$ & $1.50(0.25)$ & $1.50(0.27)$ \\
\hline $\begin{array}{l}\text { Serum apolipoprotein B } \\
\text { (mmol/L) }\end{array}$ & $1.10(0.28)$ & $1.07(0.27)$ \\
\hline Blood glucose (mmol/L) & $5.45(0.52)$ & $5.49(0.56)$ \\
\hline $\mathrm{HbA}_{1 c}(\%)$ & $5.49(0.31)$ & $5.49(0.31)$ \\
\hline Serum insulin (pmol/L) & $67(27,207)$ & $68(23,189)$ \\
\hline Serum C-peptide (pmol/L) & $836(443,1645)$ & $819(412,1666)$ \\
\hline Serum sRAGE (pg/mL) & $1239(469)$ & $1169(445)$ \\
\hline HOMA-IR & $2.70(1.00,8.48)$ & $2.84(0.86,8.15)$ \\
\hline
\end{tabular}

Data are shown as prevalence or as mean (s.D.) for normally distributed data, and median (5th, 95th percentiles) for non-normal data. * $P<0.05$, Student's $t$-test.

25(OH)D, cholecalciferol; BMI, body mass index; BP, blood pressure; HbA1c, glycosylated haemoglobin; HOMA-IR, Homeostatic Model Assessment for Insulin Resistance; PTH, parathyroid hormone; SRAGE, serum human receptors for advanced glycation end products.

Two hundred and eight subjects in the vitamin D group and 203 in the placebo group completed the study. The compliance rate was very high; $15 \%$ of the subjects had a compliance rate between 84 and 100\%, and the rest a compliance rate of $100 \%$ or higher.

In the vitamin D group, mean serum 25(OH)D levels increased to $88.7 \mathrm{nmol} / \mathrm{L}$, whereas there was a slight decrease in the placebo group to $30.6 \mathrm{nmol} / \mathrm{L}$. Except for a decrease in serum PTH and an increase in serum creatinine in the vitamin D group, there were no significant changes in any of the measured parameters between the vitamin D and the placebo groups at the end of the study (Table 2). Thirty subjects in the vitamin D group and 36 subjects in the placebo group used blood pressure-lowering drugs, and 16 and 32 subjects used lipid-lowering drugs, respectively. The lack of effect on blood pressure and lipids was seen also when subjects using blood pressureor lipid-lowering drugs were excluded (data not shown).

\section{Subgroup analyses}

\section{Effect of baseline and end of study serum 25(OH)D}

Subgroup analyses on subjects with baseline serum 25(OH) $\mathrm{D}<40 \mathrm{nmol} / \mathrm{L}$, and for those in the vitamin $\mathrm{D}$ group with end of study serum $25(\mathrm{OH}) \mathrm{D}>70 \mathrm{nmol} / \mathrm{L}(n=136)$ and those in the placebo group with end of study $25(\mathrm{OH}) \mathrm{D}$ $<40 \mathrm{nmol} / \mathrm{L}(n=127)$ were performed. In this subgroup there were again significant differences in delta values for serum PTH and creatinine. In addition, delta sRAGE was significantly $(P<0.05)$ higher in the vitamin $\mathrm{D}$ group, whereas no significant difference was found for the other delta values (Table 3). Further analysis with lowering the cut-off baseline value to $30 \mathrm{nmol} / \mathrm{L}$ was also performed ( 87 subjects in the vitamin $\mathrm{D}$ and 77 subjects in the placebo group), which yielded similar results (data not shown).

\section{Effects of baseline blood pressure, baseline serum lipids and baseline HOMA-IR}

There were no significant interactions between baseline levels of blood pressure, serum lipids and HOMA-IR and randomization status in regard to the delta values. To further explore if subjects more exposed to the risk factors would benefit from vitamin D supplementation, separate analyses were made in subjects with baseline level of the risk factor above the median for the cohort (or below for HDL-cholesterol and apolipoprotein A1) combined with baseline serum $25(\mathrm{OH}) \mathrm{D}<40 \mathrm{nmol} / \mathrm{L}$ and the expected end of study response in serum $25(\mathrm{OH}) \mathrm{D}$. However, this did not show any significant benefit from the vitamin D supplementation (Supplementary Table 1, see section on supplementary data given at the end of this article).

\section{Side effects}

No serious study-related side effects were recorded. Two subjects developed hypercalcemia (serum calcium $=2.57 \mathrm{mmol} / \mathrm{L}$ ); one male whose serum calcium normalized upon re-testing, and one female who was found to have developed primary hyperparathyroidism.

\section{Discussion}

To summarize, we found no significant effect of 4-month vitamin D supplementation on blood pressure, serum lipids, insulin resistance or other cardiovascular risk factors, regardless of baseline serum 25(OH)D levels and

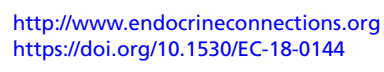

This work is licensed under a Creative Commons Attribution-NonCommercial 4.0 International License. 
Table 2 Baseline characteristics and delta values (end of study value minus baseline) in those of the vitamin D and placebo group who completed the study.

\begin{tabular}{|c|c|c|c|c|}
\hline & \multicolumn{2}{|c|}{ Baseline } & \multicolumn{2}{|c|}{ Delta values } \\
\hline & Vitamin D & Placebo & Vitamin D & Placebo \\
\hline Count & 208 & 203 & 208 & 203 \\
\hline Sex (male \%) & 53.4 & 53.2 & & \\
\hline Age (years) & $50(41,67)$ & $51(41,70)$ & & \\
\hline Smoking (\%) & 22.1 & 22.2 & & \\
\hline Serum 25(OH)D (nmol/L) & $32.6(11.1)$ & $35.1(13.6)$ & $56.2(22.1) * *$ & $-4.5(12.8)$ \\
\hline BMI $\left(\mathrm{kg} / \mathrm{m}^{2}\right)$ & $27.9(5.1)$ & $27.8(4.7)$ & $0.18(0.68)$ & $0.12(0.70)$ \\
\hline Systolic BP $(\mathrm{mmHg}) * * *$ & $122(13)$ & 123 (13) & $0.2(7.8)$ & $-0.9(7.2)$ \\
\hline Diastolic BP $(\mathrm{mmHg}) * * *$ & $77(9)$ & $77(9)$ & $0.4(4.8)$ & $-0.5(4.6)$ \\
\hline Serum creatinine ( $\mu \mathrm{mol} / \mathrm{L})$ & $70.5(11.8) *$ & $72.6(13.3)$ & $1.0(5.8) *$ & $-0.1(5.1)$ \\
\hline Serum calcium (mmol/L) & $2.27(0.07)$ & $2.27(0.07)$ & $0.01(0.07)$ & $0.00(0.06)$ \\
\hline Serum PTH (pmol/L) & $6.2(4.1,11.2)$ & $6.68(4.3,10.4)$ & $-0.76(1.39) * *$ & $0.54(1.49)$ \\
\hline Serum triglycerides $(\mathrm{mmol} / \mathrm{L}) * * * *$ & $1.20(0.60,2.60)$ & $1.10(0.60,2.50)$ & $0.00(-0.50,0.90)$ & $0.00(-0.60,0.70)$ \\
\hline Serum cholesterol $(\mathrm{mmol} / \mathrm{L}) * * * *$ & $5.22(0.95)$ & $5.15(0.95)$ & $0.11(0.52)$ & $0.03(0.58)$ \\
\hline Serum LDL-cholesterol $(\mathrm{mmol} / \mathrm{L}) * * * *$ & $3.55(0.89)$ & $3.46(0.91)$ & $0.11(0.51)$ & $0.04(0.53)$ \\
\hline Serum HDL-cholesterol (mmol/L)**** & $1.30(0.90,2.20)$ & $1.35(0.80,2.20)$ & $-0.02(0.18)$ & $-0.01(0.16)$ \\
\hline Serum apolipoprotein A1 $(\mathrm{mmol} / \mathrm{L}) * * * *$ & $1.50(0.25)$ & $1.50(0.28)$ & $-0.03(0.15)$ & $-0.03(0.15)$ \\
\hline Serum apolipoprotein B (mmol/L) $* * * *$ & $1.10(0.28)$ & $1.07(0.27)$ & $0.04(0.15)$ & $0.04(0.15)$ \\
\hline Blood glucose (mmol/L) & $5.45(0.51)$ & $5.50(0.56)$ & $0.02(0.41)$ & $-0.02(0.40)$ \\
\hline $\mathrm{HbA}_{1 \mathrm{c}}(\%)$ & $5.49(0.31)$ & $5.50(0.32)$ & $0.04(0.15)$ & $0.03(0.15)$ \\
\hline Serum insulin (pmol/L) & $67(27,199)$ & $69(23,189)$ & $4(-45,59)$ & $3(-51,78)$ \\
\hline Serum C-peptide (pmol/L) & $838(450,1644)$ & $833(412,1666)$ & $43(205)$ & $4(216)$ \\
\hline Serum sRAGE (pg/mL) & $1230(465)$ & $1167(451)$ & $145(267)$ & $108(289)$ \\
\hline HOMA-IR & $2.70(1.00,8.43)$ & $2.89(0.86,8.15)$ & $0.15(-2.03,2.61)$ & $0.11(-2.73,3.30)$ \\
\hline
\end{tabular}

Data are shown as prevalence, mean (s.D.) for normally distributed data, and median (5th, 95th percentiles) for non-normal data.

${ }^{*} P<0.05, * * P<0.01$ vs placebo group. For baseline values, Student's $t$-test, for delta values linear regression with age, gender and baseline value as covariates; $* * *$ Two subjects in the vitamin $D$ and four subjects in the placebo group excluded due to change in use of blood pressure medication during the study; $* * * *$ Three subjects in the vitamin $D$ and one subject in the placebo group excluded due to change in use of lipid-lowering medication during the study.

25(OH)D, cholecalciferol; BMI, body mass index; BP, blood pressure; HbA1C, glycosylated haemoglobin; HOMA-IR, Homeostatic Model Assessment for Insulin Resistance; PTH, Parathyroid Hormone; sRAGE, serum human receptors for advanced glycation end products.

risk factors profile. This is in agreement with the recently published study by Seibert et al. (16).

The indications for an association between vitamin $\mathrm{D}$ and CVDs and their risk factors are substantial. There are numerous prospective, observational studies showing these relations, and their corresponding meta-analyses and systematic reviews are all confirmative $(3,12,13,14$, $15,24)$. Furthermore, the vitamin D receptor is found in blood vessels, as well as in beta-cells and adipocytes (1), and effect of vitamin D on the RAS has been demonstrated in experimental animals (6). However, showing a causal relationship in interventional trials has been difficult, which could be explained by underpowered studies and not including subjects with vitamin D insufficiency (serum $25(\mathrm{OH}) \mathrm{D}<50 \mathrm{nmol} / \mathrm{L}$ ) or deficiency (serum 25(OH)D $<30 \mathrm{nmol} / \mathrm{L}$ ), as defined by the Institute of Medicine (20).

To account for this, we invited a large group of subjects with low serum $25(\mathrm{OH}) \mathrm{D}$ levels, and still the results were negative, with no improvement in the cardiovascular risk factors profile. Since we included subjects based on serum 25(OH)D levels measured up to 2 months prior to start

$\begin{array}{lr}\text { http://www.endocrineconnections.org } & \text { ○ } 2018 \text { The authors } \\ \text { https://doi.org/10.1530/EC-18-0144 } & \text { Published by Bioscientifica Ltd }\end{array}$

of the study, some subjects had serum 25(OH)D levels $>40 \mathrm{nmol} / \mathrm{L}$ at baseline. However, even when restricting the analyses to subjects with baseline serum 25(OH) D levels $<40 \mathrm{nmol} / \mathrm{L}$ (or even $<30 \mathrm{nmol} / \mathrm{L}$ ) and with the expected increase in serum $25(\mathrm{OH}) \mathrm{D}$ in the vitamin $\mathrm{D}$ group and lack of increase in the placebo group, there was no improvement in the results in favour of vitamin $\mathrm{D}$.

If lack of vitamin $\mathrm{D}$ is causally related to a definite risk factor, it is reasonable to believe that supplementation would be most efficient in the subjects with the highest risk level. To explore this, we examined potential interactions between baseline level of the risk factors and randomization status regarding the outcomes, but found no such interactions. Furthermore, we did stratified analyses of subjects with blood pressure, lipid and HOMA-IR values above the median for the cohort, combined with low baseline serum $25(\mathrm{OH}) \mathrm{D}$; but again, no significant effects of vitamin D were found.

Previous studies on vitamin D and lipid and glucose metabolism have generally included standard measures like triglycerides and cholesterols, glucose, insulin and $\mathrm{HbA}_{1 \mathrm{c}}$.

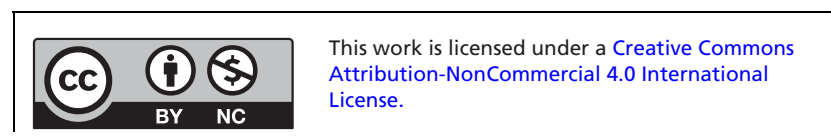


the lack of/or minor effect in Mendelian randomization studies give strong support to the results from the clinical intervention studies

CVD risk factors are surrogate endpoints for clinical disease, and the true test of benefit from vitamin D supplementation is of course prevention of disease and reduction in mortality. One large RCT testing this, the ViDa study from New Zealand that included 5110 subjects, has recently been published and found no effect on cardiovascular events (31). Several other large vitamin D RCTs are ongoing, with results expected within a few years $(32,33)$. Unfortunately, even these large studies might not give the definite answer as most of the subjects included probably are vitamin D sufficient (34). Therefore, large RCTs with inclusion of vitamin D-deficient subjects and surrogate endpoint, like our study, are of importance.

Our study has several limitations. We aimed to include 600 subjects with a mean serum 25(OH)D of $30 \mathrm{nmol} / \mathrm{L}$, but were only able to include 422 subjects with a mean serum 25(OH)D level of $34 \mathrm{nmol} / \mathrm{L}$. However, we find it unlikely that inclusion of 200 more subjects would have changed the results in favour of the vitamin D supplementation as none of the observations were even close to reach statistical significance. Similarly, we find it unlikely that our negative results were due to the inclusion of subjects with slightly higher serum $25(\mathrm{OH})$ $\mathrm{D}$ levels than anticipated, as sub-group analyses based on baseline as well as on final serum $25(\mathrm{OH}) \mathrm{D}$ levels did not change the results in favour of vitamin $\mathrm{D}$.

Although we could invite the subjects with the lowest serum 25(OH)D levels in a population-based study including more than 21,000 subjects, only 12 of our subjects had serum $25(\mathrm{OH}) \mathrm{D}<15 \mathrm{nmol} / \mathrm{L}$. We therefore cannot exclude effects on the risk factors in subjects with more profound vitamin D deficiency. We did stratified analyses on the subjects with high risk factors combined with low serum $25(\mathrm{OH})$ D levels (which is the ideal groups to study), but such stratification reduced the number of subjects considerably and accordingly, the statistical power was limited. The intervention time was only 4 months, and we cannot rule out that a longer intervention (in particular for insulin resistance that is strongly related to body weight) might have given different results. We used weekly doses, where daily doses that result in not only elevated serum 25(OH)D levels, but also increased serum cholecalciferol levels, would possibly be more biologically efficient (35). Furthermore, it might have been better if the entire study had been performed during the winter months to avoid endogenous synthesis of vitamin D in the skin.

$$
\text { http://www.endocrineconnections.org }
$$

Additionally, there are findings that suggest people may have varying molecular responses to vitamin $\mathrm{D}$ and therefore may need different supplementation/ intervention doses. This has been conceptualized as a personal vitamin $\mathrm{D}$ response index, based on the epigenetic response and gene transcription following vitamin D supplementation (36). We did not have that information available for our participants, but might be relevant to include in future studies.

On the other hand, our study has also several strengths. The expected fall in serum PTH in the vitamin D group provided our study an intern validity. Our RCT is, to our knowledge, the largest conducted RCT so far in vitamin D-insufficient and -deficient subjects with change in CVD risk factors profile as primary endpoint. The study was performed with strict adherence to RCT rules, and the vitamin D dose given was sufficient to increase serum 25(OH)D levels adequately. Moreover, we used blood pressure measurements from 2 days both at start and end of the study and included a wide range of lipid and glucose metabolism parameters, and the dropout rate was low and the compliance high.

The association between serum 25(OH)D levels and CVD risk factors in observational studies is most likely due to confounding factors, as we have previously reported for serum lipids based on cross-sectional data (37). In addition, there is always a high probability of reverse causation for vitamin D and health; good health (which is associated with health predictors like blood pressure, lipids and glucose metabolism) probably allows people to stay more outdoors and get increased sun exposure, and is therefore the driver of the vitamin $\mathrm{D}$ association.

In conclusion, vitamin D supplementation does not improve the cardiovascular risk factors blood pressure, lipids or insulin resistance, with the possible exception of serum sRAGE. This does not exclude an effect in those with severe vitamin D deficiency, but these subjects should be treated with vitamin $\mathrm{D}$ for skeletal health reasons regardless of CVD risk factors.

\section{Supplementary data}

This is linked to the online version of the paper at https://doi.org/10.1530/ EC-18-0144.

\section{Declaration of interest}

The authors declare that there is no conflict of interest that could be perceived as prejudicing the impartiality of the research reported.

This work is licensed under a Creative Commons Attribution-NonCommercial 4.0 International License. 


\section{Funding}

The present study was supported by grants from the North Norway Regional Health Authorities (grant number 6856/SFP1029-12) and UiT The Arctic University of Norway.

\section{Acknowledgements}

The great assistance from the staff at the Clinical Research Unit (and in particular Bjørg Skog Høgset and Britt-Ann Winther Eilertsen) and the Department of Medical Biochemistry at the University Hospital of North Norway is gratefully acknowledged.

\section{References}

1 Christakos S, Dhawan P, Verstuyf A, Verlinden L \& Carmeliet G. Vitamin D: metabolism, molecular mechanism of action, and pleiotropic effects. Physiological Reviews 201696 365-408. (https:// doi.org/10.1152/physrev.00014.2015)

2 Holick MF. Vitamin D deficiency. New England Journal of Medicine 2007357 266-281. (https://doi.org/10.1056/NEJMra070553)

3 Wang L, Song Y, Manson JE, Pilz S, März W, Michaëlsson K, Lundqvist A, Jassal SK, Barrett-Connor E, Zhang C, et al. Circulating 25-hydroxy-vitamin D and risk of cardiovascular disease: a meta-analysis of prospective studies. Circulation: Cardiovascular Quality and Outcomes 20125 819-829. (https://doi.org/10.1161/ CIRCOUTCOMES.112.967604)

4 Jorde R, Figenschau Y, Emaus N, Hutchinson M \& Grimnes G. Serum 25-hydroxyvitamin D levels are strongly related to systolic blood pressure but do not predict future hypertension. Hypertension 201055 792-798. (https://doi.org/10.1161/ HYPERTENSIONAHA.109.143990)

5 Scragg R, Sowers M \& Bell C. Serum 25-hydroxyvitamin D, ethnicity, and blood pressure in the Third National Health and Nutrition Examination Survey. American Journal of Hypertension 200720 713-719. (https://doi.org/10.1016/j.amjhyper.2007.01.017)

6 Vaidya A \& Williams JS. The relationship between vitamin D and the renin-angiotensin system in the pathophysiology of hypertension, kidney disease, and diabetes. Metabolism 201261 450-458. (https:// doi.org/10.1016/j.metabol.2011.09.007)

7 Jorde R, Figenschau Y, Hutchinson M, Emaus N \& Grimnes G. High serum 25-hydroxyvitamin D concentrations are associated with a favorable serum lipid profile. European Journal of Clinical Nutrition 201064 1457-1464. (https://doi.org/10.1038/ejcn.2010.176)

8 Miettinen ME, Kinnunen L, Leiviska J, Keinänen-Kiukaanniemi S, Korpi-Hyövälti E, Niskanen L, Oksa H, Saaristo T, Tuomilehto J, Vanhala M, et al. Association of serum 25-hydroxyvitamin D with lifestyle factors and metabolic and cardiovascular disease markers: population-based cross-sectional study (FIN-D2D). PLoS ONE 20149 e100235. (https://doi.org/10.1371/journal.pone.0100235)

9 Chiu KC, Chu A, Go VL \& Saad MF. Hypovitaminosis D is associated with insulin resistance and beta cell dysfunction. American Journal of Clinical Nutrition 200479 820-825. (https://doi.org/10.1093/ ajcn/79.5.820)

10 Grimnes G, Figenschau Y, Almas B \& Jorde R. Vitamin D, insulin secretion, sensitivity, and lipids: results from a case-control study and a randomized controlled trial using hyperglycemic clamp technique. Diabetes 201160 2748-2757. (https://doi.org/10.2337/db11-0650)

11 Chow EC, Magomedova L, Quach HP, Patel R, Durk MR, Fan J, Maeng HJ, Irondi K, Anakk S, Moore DD, et al. Vitamin D receptor activation down-regulates the small heterodimer partner and increases CYP7A1 to lower cholesterol. Gastroenterology 2014146 1048-1059. (https://doi.org/10.1053/j.gastro.2013.12.027)

12 Beveridge LA, Struthers AD, Khan F, Jorde R, Scragg R, Macdonald HM, Alvarez JA, Boxer RS, Dalbeni A, Gepner AD, et al.
Effect of vitamin D supplementation on blood pressure: a systematic review and meta-analysis incorporating individual patient data. JAMA Internal Medicine 2015175 745-754. (https://doi.org/10.1001/ jamainternmed.2015.0237)

13 Wang H, Xia N, Yang Y \& Peng DQ. Influence of vitamin D supplementation on plasma lipid profiles: a meta-analysis of randomized controlled trials. Lipids in Health and Disease 20121142. (https://doi.org/10.1186/1476-511X-11-42)

14 Challoumas D. Vitamin D supplementation and lipid profile: what does the best available evidence show? Atherosclerosis 2014235 130-139. (https://doi.org/10.1016/j.atherosclerosis.2014.04.024)

15 Poolsup N, Suksomboon N \& Plordplong N. Effect of vitamin D supplementation on insulin resistance and glycaemic control in prediabetes: a systematic review and meta-analysis. Diabetic Medicine 201633 290-299. (https://doi.org/10.1111/dme.12893)

16 Seibert E, Lehmann U, Riedel A, Ulrich C, Hirche F, Brandsch C, Dierkes J, Girndt M \& Stangl GI. Vitamin D3 supplementation does not modify cardiovascular risk profile of adults with inadequate vitamin D status. European Journal of Nutrition 201756 621-634. (https://doi.org/10.1007/s00394-015-1106-8)

17 Jorde R \& Grimnes G. Vitamin D and health: the need for more randomized controlled trials. Journal of Steroid Biochemistry and Molecular Biology 2015148 269-274. (https://doi.org/10.1016/j. jsbmb.2015.01.021)

18 Jacobsen BK, Eggen AE, Mathiesen EB, Wilsgaard T \& Njolstad I. Cohort profile: the Tromso Study. International Journal of Epidemiology 201241 961-967. (https://doi.org/10.1093/ije/dyr049)

19 Jorde R, Sollid ST, Svartberg J, Schirmer H, Joakimsen RM, Njølstad I, Fuskevåg OM, Figenschau Y \& Hutchinson MY. Vitamin D 20,000 IU per week for five years does not prevent progression from prediabetes to diabetes. Journal of Clinical Endocrinology and Metabolism 2016101 1647-1655. (https://doi.org/10.1210/jc.2015-4013)

20 Ross AC, Manson JE, Abrams SA, Aloia JF, Brannon PM, Clinton SK, Durazo-Arvizu RA, Gallagher JC, Gallo RL, Jones G, et al. The 2011 report on dietary reference intakes for calcium and vitamin $\mathrm{D}$ from the Institute of Medicine: what clinicians need to know. Journal of Clinical Endocrinology and Metabolism 201196 53-58. (https://doi. org/10.1210/jc.2010-2704)

21 Sollid ST, Hutchinson MY, Fuskevag OM, Figenschau Y, Joakimsen RM, Schirmer H, Njølstad I, Svartberg J, Kamycheva E \& Jorde R. No effect of high-dose vitamin D supplementation on glycemic status or cardiovascular risk factors in subjects with prediabetes. Diabetes Care 201437 2123-2131. (https://doi. org/10.2337/dc14-0218)

22 Heier M, Margeirsdottir HD, Gaarder M, Stensæth KH, Brunborg C, Torjesen PA, Seljeflot I, Hanssen KF \& Dahl-Jørgensen K. Soluble RAGE and atherosclerosis in youth with type 1 diabetes: a 5-year follow-up study. Cardiovascular Diabetology 201514 126. (https://doi. org/10.1186/s12933-015-0292-2)

23 Matthews DR, Hosker JP, Rudenski AS, Naylor BA, Treacher DF \& Turner RC. Homeostasis model assessment: insulin resistance and beta-cell function from fasting plasma glucose and insulin concentrations in man. Diabetologia 198528 412-419. (https://doi. org/10.1007/BF00280883)

24 Grubler MR, Marz W, Pilz S, Grammer TB, Trummer C, Müllner C, Schwetz V, Pandis M, Verheyen N, Tomaschitz A, et al. Vitamin-D concentrations, cardiovascular risk and events - a review of epidemiological evidence. Reviews in Endocrine and Metabolic Disorders 201718 259-272. (https://doi.org/10.1007/s11154-0179417-0)

25 McQueen MJ, Hawken S, Wang X, Ounpuu S, Sniderman A, Probstfield J, Steyn K, Sanderson JE, Hasani M, Volkova E, et al. Lipids, lipoproteins, and apolipoproteins as risk markers of myocardial infarction in 52 countries (the INTERHEART study): a case-control study. Lancet 2008372 224-233. (https://doi. org/10.1016/S0140-6736(08)61076-4)

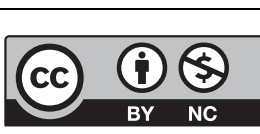

This work is licensed under a Creative Commons Attribution-NonCommercial 4.0 International License. 
26 Selvin E, Halushka MK, Rawlings AM, Hoogeveen RC, Ballantyne CM, Coresh J \& Astor BC. sRAGE and risk of diabetes, cardiovascular disease, and death. Diabetes 201362 2116-2121. (https://doi.org/10.2337/db12-1528)

27 Irani M, Minkoff H, Seifer DB \& Merhi Z. Vitamin D increases serum levels of the soluble receptor for advanced glycation end products in women with PCOS. Journal of Clinical Endocrinology and Metabolism 201499 E886-E890. (https://doi.org/10.1210/jc.2013-4374)

28 Wang TJ, Zhang F, Richards JB, Kestenbaum B, van Meurs JB, Berry D, Kiel DP, Streeten EA, Ohlsson C, Koller DL, et al. Common genetic determinants of vitamin D insufficiency: a genome-wide association study. Lancet 2010376 180-188. (https://doi.org/10.1016/S01406736(10)60588-0)

29 Vimaleswaran KS, Cavadino A, Berry DJ, LifeLines Cohort Study Investigators, Jorde R, Dieffenbach AK, Lu C, Alves AC, Heerspink HJ, Tikkanen E, et al. Association of vitamin D status with arterial blood pressure and hypertension risk: a mendelian randomisation study. Lancet Diabetes and Endocrinology 20142 719-729. (https://doi. org/10.1016/S2213-8587(14)70113-5)

30 Ooi EM, Afzal S \& Nordestgaard BG. Elevated remnant cholesterol in 25-hydroxyvitamin D deficiency in the general population: mendelian randomization study. Circulation: Cardiovascular Genetics 20147 650-658. (https://doi.org/10.1161/CIRCGENETICS.113.000416)

31 Scragg R, Stewart AW, Waayer D, Lawes CMM, Toop L, Sluyter J, Murphy J, Khaw KT, Camargo CA Jr. Effect of monthly high-dose vitamin D supplementation on cardiovascular disease in the vitamin D assessment study: a randomized clinical trial.
JAMA Cardiology 20172 608-616. (https://doi.org/10.1001/ jamacardio.2017.0175)

32 Manson JE, Bassuk SS, Lee IM, Cook NR, Albert MA, Gordon D, Zaharris E, Macfadyen JG, Danielson E, Lin J, et al. The VITamin D and OmegA-3 TriaL (VITAL): rationale and design of a large randomized controlled trial of vitamin $\mathrm{D}$ and marine omega-3 fatty acid supplements for the primary prevention of cancer and cardiovascular disease. Contemporary Clinical Trials 201233 159-171. (https://doi.org/10.1016/j.cct.2011.09.009)

33 Neale RE, Armstrong BK, Baxter C, Duarte Romero B, Ebeling P, English DR, Kimlin MG, McLeod DS, O Connell RL, van der Pols JC, et al. The D-Health Trial: a randomized trial of vitamin D for prevention of mortality and cancer. Contemporary Clinical Trials 2016 48 83-90. (https://doi.org/10.1016/j.cct.2016.04.005)

34 Pilz S, Rutters F \& Dekker JM. Disease prevention: vitamin D trials. Science 2012338 883. (https://doi.org/10.1126/ science.338.6109.883-c)

35 Jorde R \& Grimnes G. Serum cholecalciferol may be a better marker of vitamin D status than 25-hydroxyvitamin D. Medical Hypotheses 2018111 61-65. (https://doi.org/10.1016/j.mehy.2017.12.017)

36 Carlberg C \& Haq A. The concept of the personal vitamin D response index. Journal of Steroid Biochemistry and Molecular Biology 2018175 12-17. (https://doi.org/10.1016/j.jsbmb.2016.12.011)

37 Jorde R \& Grimnes G. Exploring the association between serum 25-hydroxyvitamin $\mathrm{D}$ and serum lipids-more than confounding? European Journal of Clinical Nutrition 201872 526-533. (https://doi. org/10.1038/s41430-018-0088-z)

\section{Received in final form 9 May 2018}

Accepted 15 May 2018

Accepted Preprint published online 15 May 2018
This work is licensed under a Creative Commons Attribution-NonCommercial 4.0 International License. 